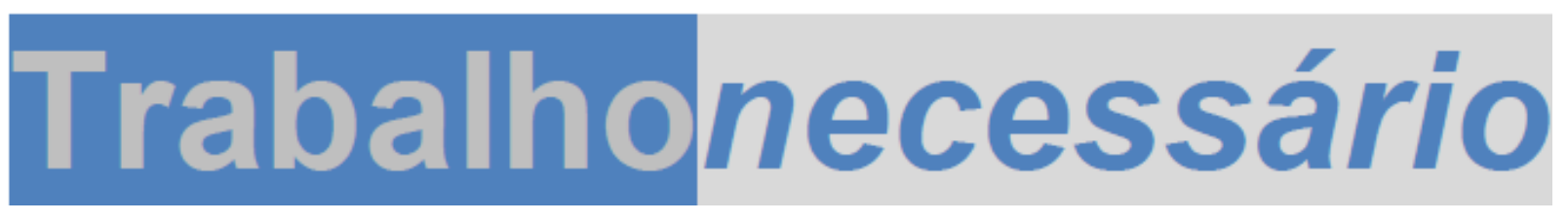

Issn: 1808 - 799X

ano 11, no $17-2013$

\title{
A EDUCAÇÃO AMBIENTAL, TRABALHO E AS RELAÇÕES CAPITALISTAS
}

\author{
Cinara Menegotto Cavalheiro Karam ${ }^{1}$ \\ Luis Fernando Minasi ${ }^{2}$ \\ Alexandre Macedo Pereira ${ }^{3}$ \\ Marta Regina Cezar-Vaz ${ }^{4}$
}

\section{RESUMO:}

Neste artigo, enfocamos a relação capital-trabalho como importante fenômeno que determina as relações de sociabilidade ao logo da história da humanidade e a função da Educação Ambiental neste processo complexo. O trabalho é um ato eminentemente humano, portanto, teleológico e categoria fundante do ser social e que ao longo da história, foi sendo modificado pelo processo de desenvolvimento do modo de produção capitalista e instituição da propriedade privada. Abordamos aqui, o processo histórico da relação trabalho-trabalhador e suas implicações na vida da classe trabalhadora, demonstrando que essa relação produz a subsunção do trabalhador ao capital, ocorrendo o domínio deste sobre todas as atividades humanas. Apresentaremos também como a Educação Ambiental se interpõe neste processo de coisificação do trabalho em uma perspectiva crítica. Trata-se aqui de um olhar cujo fundamento ontológico da educação ambiental centra-se na superação do modo de produção capitalista e, portanto, na superação da visão idealista da natureza e do homem nesta relação. Este trabalho é de caráter teórico resultante de uma ampla revisão bibliográfica.

Palavras-chave: trabalho-trabalhador, capital-trabalho, educação ambiental.

\footnotetext{
${ }^{1}$ Doutoranda em Educação Ambiental, Mestre em Educação Ambiental pelo programa de PósGraduação em Educação Ambiental (PPGEA) na Universidade Federal do Rio Grande - FURG e Médica. E-mail: cinarakaram@hotmail.com

${ }_{2}^{2}$ Prof. Doutor da Universidade Federal do Rio Grande - FURG. E-mail: ifminasi@terra.com.br

3 Doutorando em Educação Ambiental pelo programa de Pós-Graduação em Educação Ambiental (FURG), Mestre em Gestão Ambiental pelo Programa de Gestão de Recursos Naturais e Desenvolvimento Local na Amazônia - PPGEDAM/UFPA. E-mail: c.cpa2008@hotmail.com

${ }^{4}$ Professora Dra. Da Universidade Federal do Rio Grande - FURG. Professora do curso de enfermagem e no programa em Educação Ambiental (PPGEA).
} 


\title{
Trabalhonecessário
}

Issn: 1808 - 799X

ano 11, no $17-2013$

\section{ENVIRONMENTAL EDUCATION, WORK AND THE CAPITALIST RELATIONSHIPS}

\begin{abstract}
:
In this paper, we focus on the capital-labor ratio as an important phenomenon that determines the relations of sociability throughout the history of humanity and the role of Environmental Education in this complex process. Work is an eminently human act, therefore teleological and a foundational category of the social being which, throughout history, has been modified by the development process of the capitalist mode of production and the private property. We address here, the historical process of the work-worker relationship and its implications in the life of the working class, demonstrating the subsumption of the worker to capital, resulting in the dominance of this over all human activities. We will also present how Environmental Education intervenes in this process of making labor into a concrete object, in a critical perspective. This is an overwiew, which ontological foundation of Environmental Education focuses on overcoming the capitalist mode of production and hence, overcoming the idealistic view of nature and man in this relationship. This work is theoretical, resulting from an extensive literature review.
\end{abstract}

Keywords: work-worker, capital- labor, environmental education. 


\section{Trabalhonecessário}

Issn: 1808 - 799X

ano 11, no $17-2013$

\section{INTRODUÇÃO:}

Explicações científicas para os múltiplos fenômenos que envolvem a vida e suas relações sempre se fizeram presentes ao longo da existência humana. O grande e intenso avanço do pensamento científico-filosófico, em todos os tempos, também provocou, em determinadas etapas da história, destituição de inúmeras ideias e teorias, fazendo surgir novas explicações que se opõem a tantos outros modos de entender a vida, o ser humano e a sociedade. Esse é o caso de posicionamentos desenvolvidos por Marx e Engels em relação à sociedade capitalista e seus fundamentos.

Ao fazermos uma imersão na história com o objetivo de recompor a trajetória dos modos de produção e reprodução social, é possível identificar o trabalho na sua condição ontológica, compreendendo portanto, que este é uma determinação inerente ao ser humano, e, resultado da complexificação do modo de produção e organização social. Quanto mais o modo de produção e reprodução social se complexifica o trabalho perde sua condição de categoria fundante e assume a forma de mercadoria (valor-de-troca) conseqüentemente passa a ser cercado pela injustiça, exploração e inequidades, sob a égide do capital.

Neste artigo, discutimos as relações de produção e reprodução da sociedade capitalista e o trabalho. Em decorrência desse objetivo central, abordamos o processo histórico dessa relação, evidenciando a subsunção do trabalho ao capital e consequetemente o caráter teleológico do trabalho neste modo de organização social. Desse modo, esse fenômeno, aliado ao domínio do capital sobre todas as atividades humanas, levou à subsunção da vida do trabalhador ao capital, ou seja, a subsunção real da vida social ao capital. Portanto, privilegiamos a referente análise acerca do capital-trabalho na constituição e no contexto da sociedade capitalista. 


\section{Trabalhonecessário}

Issn: 1808 - 799X

ano $11, \mathrm{n}=17-2013$

\section{1 - TRABALHO COMO MEDIADOR DA EXISTÊNCIA HUMANA}

Como determinação eminentemente humana, o trabalho é uma categoria central para compreender o modo de produção social e portanto, é ele o mediador, não o único, das relações sociais. $E$ assim o é porque o trabalho é a atividade humana que transforma a natureza e o faz para criar as condições necessárias a reprodução social. Segundo Lessa (2012, p. 25):

[...] é a atividade humana que transforma a natureza nos bens necessários à reprodução social. É no trabalho que se efetiva o salto ontológico que retira a existência humana das determinações meramente biológicas. Sendo assim, não pode haver existência social sem o trabalho.

É importante colocar em evidencia que a existência social não se circunscreve ao trabalho, esta é muito mais do que o trabalho, o trabalho é uma categoria social que só existe como parte de um conjunto das relações sociais. Por isso diz Lessa (2012, p. 25), "O próprio trabalho é uma categoria social" [...]. Sendo assim, a relação homem/natureza implica necessariamente a relação homem/homem. A relação homem/homem (relação social) contém múltiplas e variadas atividades que cumprem o objetivo de atender às necessidades humanas e, elas só podem se constituir nas relações sociais e são, portanto, teleológicas.

O trabalho, pelo contrário, é a atividade de transformação da natureza pela qual o homem constrói, concomitantemente, a si próprio como indivíduo e a totalidade social da qual é partícipe. É a categoria decisiva da autoconstrução humana, da elevação dos homens a níveis cada vez mais desenvolvidos de sociedade (LESSA, 2012, p. 26).

Desse modo, o ser humano, ao longo dos tempos, criou forma diversa à de outros seres vivos, a fim de agir para sobreviver. Segundo Marx (1991, p. 27) "O primeiro pressuposto de toda história humana é, naturalmente, a existência de indivíduos humanos vivos. O primeiro ato histórico destes 


\title{
Trabalhonecessário
}

Issn: 1808 - 799X

ano 11, no $17-2013$

indivíduos, pelo qual se distinguem dos animais, não é o fato de pensar, mas o de produzir seus meios de vida". Através de sua capacidade intelectiva, reorganizou ou modificou os recursos naturais disponíveis, conforme assinala Chassot (1994, p. 12):

\begin{abstract}
Um galho de árvore ou um fêmur tornaram-se tanto armas para defesa quanto instrumentos para apanhar um fruto em lugares altos. Pedras se revelaram objetos adequados tanto para serem utilizados como projéteis para golpear. Gradativamente, essas primitivas ferramentas foram sendo melhoradas: quebravam-se as pedras grandes para se obterem pedaços menores e na forma desejada; elas eram talhadas para que tivessem bordas cortantes; afinavam-se ramos, convertendo-os em objetos pontiagudos. Novos materiais passaram a ser utilizados para a confecção de objetos: unhas, garras, chifres, dentes, conchas, fibras vegetais (...). Com esse arsenal tecnológico tornava-se possível trabalhar os materiais disponíveis na natureza para a produção de objetos que atendessem às necessidades mais imediatas da vida.
\end{abstract}

Este intercâmbio material com a natureza é a única possibilidade de reprodução social, mesmo na contemporaneidade. A relação homem/natureza é indissociável assim como é indissociável a relação homem/homem. Mas, ser indissociável não significa ser idênticos; homem e natureza possuem distinção ontológica e segundo Marx (2008, p. 211-212) "Mas o que distingue o pior arquiteto da melhor abelha é que ele figura na mente sua construção antes de transformá-la em realidade".

É indispensável ressaltarmos que é pelo trabalho que os seres humanos garantem não só sua própria existência material, mas, também a espiritual na relação com a natureza e o meio ambiente. Isso acontece, pois, mediante a prática produtiva, ou seja, usando sua energia vital, sua força física, biológica e química para produzir os bens de que necessitam, quer na dimensão individual quer na dimensão social. Para tanto, criam meios e instrumentos com as quais "Atuando assim sobre a natureza externa e modificando-a, ao mesmo tempo modifica sua própria natureza" (MARX, 2008, p. 211).

É essa relação do ser humano com a natureza que the permite sobreviver. Todavia, ao atuar sobre a natureza objetiva, o homem constitui, 


\section{Trabalhonecessário}

Issn: 1808 - 799X

ano $11, \mathrm{n}=17-2013$

pelo trabalho, outras formas de mediação de sua existência. Nesse sentido, Severino (2004, p. 154) afirma:

Com efeito, nesse contínuo processo de produção que se dá via trabalho, os homens vão tecendo concretamente suas relações sociais, vão se organizando em sociedade, criando as instituições sociais. É a própria divisão técnica do trabalho que introduz a diferenciação dos grupos de produtores, gerando assim uma sociedade repleta de grupos hierarquizados. Além disso, a atividade do trabalho desenvolve e intensifica a atividade simbolizadora dos homens, faz com que a sua subjetividade funcione produzindo, cada vez mais, os elementos simbólicos, os bens culturais: as formas ideais da cultura, o saber comum, os mitos, as religiões, as artes, a ciência, a filosofia, os códigos, a moral, o direito etc.

O trabalho, assim entendido, constitui-se em mediação básica da existência humana. E mais: quando o contexto histórico-social não permite ao ser humano usufruir dessa condição, ele estará sendo privado da condição de humanidade, acarretando-Ihe situações alienantes, contribuindo para a perda da própria identidade, a perda da própria essência humana. Em situação como essa, o homem acaba exercendo uma atividade puramente mecânica, como se fosse um animal ou uma máquina, vivenciando um processo de autodegradação.

Entendemos, assim, que o trabalho se constitui como uma necessidade permanente dos humanos. Diferentemente dos demais seres vivos, que se adaptam ao meio ambiente, o ser humano atua sobre ele ativamente, obtendo os bens materiais indispensáveis à sua existência por meio de ação produtiva o trabalho. Portanto, a existência social não pode vir a ser sem a natureza, pois, a vida só pode existir sobre base inorgânica. Segundo Lessa (2012, p. 58), "a troca orgânica do ser social com a natureza é a mediação ontológica que possibilita que o ser social se constitua enquanto esfera ontológica particular no interior da totalidade do ser geral. Na tradição marxiana, tal mediação é o trabalho". 


\title{
Trabalhonecessário
}

Issn: 1808 - 799X

ano $11, \mathrm{n}=17-2013$

\section{2 - SOCIEDADE CAPITALISTA: A RELAÇÃO CAPITAL E TRABALHO}

A luta entre patrões (proprietários) e trabalhadores (produtores) sempre esteve presente na história da produção capitalista. Esse processo vem sendo desenvolvido desde os primórdios da humanidade, portanto é um processo histórico. As sociedades "civilizadas" foram as primeiras a se dedicaram ao comércio de bens produzidos em excesso, iniciando assim, a hierarquização das sociedades. Ao se fixar à terra e nela produzir de forma contínua, gerou-se, então, o sentido de propriedade, introduzindo modificações em relação ao trabalho.

Cortes (2006, p. 4) explicita:

\begin{abstract}
A força que trabalhava a terra também sofreu modificações com a passagem dos tempos, sendo realizado por escravos, servos ou mesmo por camponeses, o excedente da produção era recebido por fidalgos independentes ou por funcionários de uma monarquia ou de uma potência imperialista. Mas as linhas principais das relações econômicas eram sempre as mesmas: o excedente era consumido para manter um aparato militar e em parte para sustentar o padrão de vida da classe ociosa. Do trabalho sobre a terra se origina a riqueza que vai incentivar 0 desenvolvimento do trabalho artesanal; ao mesmo tempo, se intensifica o comércio, uma vez que há excedentes tanto na agricultura como na criação de animais.
\end{abstract}

Com a institucionalização da propriedade privada a produção social se complexificou e as divergências se estabeleceram sendo necessário a criação do Estado, política, exército, escola etc. As cidades ganharam força, constituindo-se como núcleos de comércio. Determinados tipos de ofícios tornaram-se indispensáveis nas cidades e os setores de trabalhos [...] "passaram a ser agrupados em corporações de pessoas que exerciam o mesmo tipo de atividade" (idem). Essas corporações foram substituídas por outros tipos de organizações, emergentes de ideias capitalistas mercantilistas. Estava instaurado, a partir de então, o confronto entre burguesia e proletariado, termos assim conceituados: 


\title{
Trabalhonecessário
}

Issn: 1808 - 799X

ano 11, no $17-2013$

\begin{abstract}
Por burguesia entendemos a classe dos capitalistas modernos, proprietários dos meios de produção social e empregadores do trabalho assalariado. Por proletariado, a classe dos operários assalariados modernos que, não possuindo meios próprios de produção, reduzem-se a vender a força de trabalho para poderem viver (NOTA DE ENGELS À EDICÃO INGLESA DE 1888. MARX; ENGELS, 2009, p. 23).
\end{abstract}

Assim, de acordo com Marx e Engels (2009, p. 24), os "[...] servos da Idade Média deram origem aos cidadãos das primeiras comunas; advindos desses cidadãos, nasceram os primeiros elementos da burguesia". O termo comuna referia-se às cidades nascentes que foram conquistadas por senhores feudais e mestres quanto à administração local autônoma e aos direitos políticos (ENGELS, nota à edição alemã do Manifesto do Partido Comunista de 1890). As grandes descobertas marítimas e o contato com os mercados da Índia, da China e da América possibilitaram e intensificaram os meios de troca, deram grande impulso à navegação, ao comércio e à indústria, [...] "favorecendo na sociedade feudal em desintegração a expansão rápida do elemento revolucionário" (ibidem, p. 25). O elemento revolucionário estava composto, principalmente, por duas dimensões: a política e a tecnológica.

A primeira dimensão referia-se à ascensão da burguesia, que desalojou as corporações. Marx e Engels (2009, p. 25) traçam, de forma contundente, 0 poder assumido pela burguesia:

Onde quer que tenha chegado o poder, a burguesia destruiu todas as relações feudais, patriarcais, idílicas. Estilhaçou, sem piedade, os variegados laços feudais que subordinavam o homem a seus superiores naturais, e não deixou subsistir entre os homens outro laço senão o interesse nu e cru, senão o frio "dinheiro vivo". Submergiu nas águas glaciais do cálculo egoísta os frêmitos sagrados da piedade exaltada, do entusiasmo cavalheiresco, do sentimentalismo pequeno-burguês. Reduziu a dignidade pessoal a simples valor de troca e, em lugar das inumeráveis liberdades estatuídas e arduamente conquistadas, erigiu a liberdade única e implacável do comércio. Em resumo, substituiu a exploração disfarçada sob ilusões religiosas e políticas pela exploração aberta, cínica, direta e brutal (ibidem, pp. 27-28).

A segunda dimensão do elemento revolucionário referia-se ao desenvolvimento tecnológico. O surgimento do vapor e do processo maquinista revolucionou a produção industrial. Dessa forma, a [...] "manufatura deu lugar à 


\section{Trabalhonecessário}

Issn: 1808 - 799X

ano $11, \mathrm{n}=17-2013$

grande indústria moderna; a classe média industrial, aos milionários da indústria, chefes de verdadeiros exércitos industriais, os burgueses modernos" (MARX; ENGELS, 2009, p. 25). No entanto, o desenvolvimento da economia capitalista:

[...] foi capaz de determinar uma curiosa situação. Mesmo produzindo riquezas em um patamar astronômico, o capitalismo ainda estava cercado por desigualdades que indicavam a diferença social e econômica das classes burguesa e operária (SOUSA, 2011, p.01).

O processo de desenvolvimento do modo de produção do capital alterou na essência do trabalho e consequentemente alterou a modo de reprodução social colocando o homem na condição de coisa (reificação). $O$ trabalho perdeu a sua essência, valor-de-uso, e passou ter como "centralidade" o valor-detroca. $O$ trabalho deixou de ser trabalho ontológico e passou a ser trabalho abstrato, sendo o trabalho abstrato uma atividade assalariada, alienada pelo capital. "Corresponde à submissão dos homens ao mercado capitalista, forma social de transformar a todos em "coisas" (reificação)" (LESSA, 2012, p. 26).

O trabalho é considerado uma mercadoria, como qualquer artigo do comércio: estar sujeito à implacável influência da concorrência e a todas as flutuações do mercado. Portanto, de acordo com Marx e Engels (2009) a mais-valia determinava a relação econômica entre proletariado e burguesia. Gomes (2008, p. 1) também elucida que a mais-valia consiste:

[...] na diferença entre o valor criado pela utilização da força de trabalho e o valor dessa força de trabalho. $O$ valor gerado pela força de trabalho desdobra-se em dois componentes: uma parte corresponde ao valor da própria força de trabalho, parcela reposta pelo salário pago; outra parte constitui o valor excedente ou mais-valia, que vai ser apropriado sob a forma de lucro. A mais-valia corresponde, portanto, ao valor do sobretrabalho, ou seja, do trabalho não pago realizado pelo trabalhador para 0 capitalista e que constitui a base da repartição de rendimentos e da acumulação de capital.

Nesse sentido, o trabalhador utiliza sua capacidade de criar, no processo de trabalho, além do valor de sua própria força de trabalho. Esse 


\section{Trabalhonecessário}

Issn: 1808 - 799X

ano 11, no $17-2013$

processo proporciona a mais-valia, que passa a ser propriedade do capitalista. Desse modo, na produção capitalista, o conceito de trabalho produtivo alterouse - deixou de ser realizado para a produção de mercadorias e passou a ocupar-se essencialmente da produção de mais-valia.

Com o avanço da tecnologia, o trabalhador deixou de ser o artífice da produção e passou a ser um simples acessório da máquina que desempenha uma ação rotineira, sem atrativos. Assim, [...] "os custos que o operário gera limitam-se aproximadamente apenas aos meios de subsistência de que necessita para manter-se e reproduzir-se. Ora, o preço de uma mercadoria - e, portanto, também do trabalho - é igual a seus custos de produção" (MARX; ENGELS, 2009, p. 35).

Quanto ao modo de produção, entendemos, a princípio, que se constitui como referência "[...] para designar a evolução histórica e prever os caminhos políticos aonde essa comunidade pode chegar" (SOUSA, 2011, p. 1). Nessa perspectiva, é, por meio do modo de produção, que se torna possível configurar uma sociedade quanto às suas relações e interrelações frente à complexidade que cerca o ser humano (MARX, 2008). De forma bastante simples, é possível afirmarmos que modo de produção é o como se produz em sociedade, a partir de dois aspectos fundamentais: o técnico e o político.

Então, o modo de produção pode ser entendido como sendo uma estrutura global, que se constitui por estruturas de menor delimitação - as estruturas regionais, como: estrutura econômica, considerada como infraestrutura; estrutura jurídico-política e estrutura ideológica, consideradas como superestruturas.

Essas estruturas não são instâncias isoladas, ainda que tenham autonomia e dinâmicas próprias. Mantêm relação dialética, permitindo, assim, o entendimento de que o modo de produção resulta da combinação específica das diversas estruturas e práticas. O modo de produção capitalista é hegemônico e está caracterizado facilmente pela exploração do homem pelo

TrabalhoNecessário - www.uff.br/trabalhonecessario; Ano 11, № 17/2013. 


\section{Trabalhonecessário}

Issn: 1808 - 799X

ano 11, no $17-2013$

homem. É possível determinar o modo de produção capitalista associado às características da sociedade: comunismo primitivo, escravatura, asiático, feudalismo, capitalismo, socialismo e comunismo. Nos contextos em que se produziu o modo de produção, torna-se possível reconhecer a forte carga político-ideológica que os influenciaram e caracterizaram (MARX, 2008).

Na relação capital-trabalho ocorrem inadequações no modo de produção de ordem diversa. A busca pelo lucro sobrepuja o valor da vida e da atividade do trabalhador, sendo que tais condições desfavoráveis venham a causar danos à saúde do trabalhador. Portanto, a burguesia, conformando definitivamente o capitalismo, relegou o respeito aos seres humanos e às instituições sociais; [...] "rasgou o véu de emoção e de sentimentalidade das relações familiares e reduziu-as a mera relação monetária" (ibidem, p. 28).

Os mesmos autores $(2009$, p. 36$)$ assim descrevem a realidade do fim do século XVIII e início do século XIX:

A indústria moderna transformou a pequena oficina do mestre artesão patriarcal na grande fábrica do capitalista industrial. Contingentes de operários, apinhados na fábrica são organizados de forma militar. São colocados como soldados rasos da indústria, sob o controle de oficiais. Não são apenas os servos da classe burguesa, do Estado burguês; são, a cada dia, a cada hora, avassalados pela máquina, pelo fiscal, pelo próprio burguês industrial. Esse despotismo é tanto mais mesquinho, mais odioso, mais exasperante, quanto mais abertamente proclama que seu fim último é o lucro.

O operário, portanto, "[...] em vez de elevar-se com o progresso da indústria, decai cada vez mais, abaixo das condições de sua própria classe" (ibidem, p. 44). 


\section{Trabalhonecessário}

Issn: 1808 - 799X

ano 11, no $17-2013$

\section{3 - EDUCAÇÃO AMBIENTAL E O CAPITAL: INTRUMENTO IDEOLÓGICO ALIENANTE OU UMA POSSIBILIDADE DE ENFRENTAMENTO DO CAPITAL?}

A análise aqui realizada leva em consideração a educação ambiental (EA) e as relações sociais no modo de produção do capital. A análise terá como pressupostos essenciais: a incorrigibilidade do capital (Mészàros), seu compromisso essencialmente com o lucro (Marx), seu poder de destruição (Hobsbwm) e por fim, o antagonismo existente entre desenvolvimento sustentável na perspectiva do capital e do Estado.

É comum, na literatura sobre EA no Brasil, a ideia que a Política Nacional de Educação Ambiental - PNEA - representa um avanço; todavia, esse recorrente pensamento nos parece equivocado e perigoso. Há nessa perspectiva um antagonismo a ser considerado: como pode o Estado (burguês) e a serviço da classe dominante elaborar leis que de fato promovam transformação, emancipação dos homens? Segundo Marx (2005), o Estado (burguês) não é a sociedade e sim, apenas uma mera representação desta. Neste contexto, Estado e Sociedade possuem interesses divergentes, portanto, estão em lados opostos.

Para Lenin (2010), o Estado é o produto da inconciliabilidade das contradições de classe. Se assim o for, pensar em leis, produzidas pelo Estado, que estejam comprometidas com a emancipação humana é uma quimera. $O$ Estado (burguês) mantém-se afastado da sociedade e a controla com seus aparelhos ideológicos e militares.

A realidade nos permite entender as razões que levam o Estado a aceitar programas de educação ambiental empresarial (PEAE). Compreender 0 porquê, mesmo as grandes empresas sendo as maiores causadoras de impactos socioambientais, o PEAE delas se volta para "ensinar" as comunidades como não impactar o meio ambiente (contradição). O PEAE 


\section{Trabalhonecessário}

Issn: 1808 - 799X

ano 11, no $17-2013$

transforma as vítimas em culpadas pelos impactos socioambientais na região, e isso tudo, legitimado pelo Estado.

Podemos afirmar, a partir do discutido até aqui, que o PEAE dos grandes empreendimentos empresarial está dentro do estabelecido pela lei 9795/99, o que obviamente não representa nenhuma novidade, uma vez que, esta lei foi feita e implementada para atender aos interesses do capital e não aos interesses das comunidades. Por isso "não haver ilegalidade" da empresa. Imaginar que uma empresa transnacional iria permitir que o Estado (burguês) elaborasse leis que prejudicasse a expansão do capital, favorecesse a um projeto de EA emancipatório e transformador, é uma ingenuidade dos intelectuais do campo da EA.

As grandes empresas com seu poderio econômico contratam as mais conceituadas empresas e profissionais para desenvolver o seu PEAE, com o objetivo de desarticular as comunidades da região impedindo assim, qualquer possibilidade de enfrentamento. Neste contexto a Educação Ambiental tem claro papel ideológico de controle sobre as comunidades afetadas. Não poderia ser diferente, o capitalismo é incorrigível (Mészáros) e devastador (Hobsbwm), essa é sua essência, portanto, essa é a essência dos PEAE.

Por ser essa a essência do PEAE, todas as ações desse programa estão voltadas para atividades escolares utilitaristas, reprodutoras e alienantes. Os problemas reais de impactos socioambientais e suas relações com o modo de produção capitalista não são contemplados nestes programas. Os problemas causados pela empresa não são também trabalhados nesse programa e a comunidade sem elementos de instrumentalização capazes de qualificá-los para o enfrentamento, ficam sem condições de mobilização.

Portanto, a EA que se pretende crítica, precisa abandonar a ideia de que - Estado pode oferecer leis que atendam aos anseios emancipatórios e transformadores da sociedade. Tem que abandonar a esperança da conciliação entre modo de produção capitalista e justiça socioambiental. Uma

TrabalhoNecessário - www.uff.br/trabalhonecessario; Ano 11, № 17/2013. 


\section{Trabalhonecessário}

Issn: 1808 - 799X

ano $11, \mathrm{n}=17-2013$

educação ambiental que se pretende crítica e emancipatória precisa romper como o modo de produção capitalista e necessita assim, trazer para o centro do seu debate o trabalho enquanto categoria fundante.

A educação ambiental precisa incorporar em suas discussões a inseparabilidade do homem e a natureza e as implicações desta totalidade. Não é fazendo apologia a natureza "pura", sem estabelecer a relação homem natureza, que a educação ambiental contribuirá para questionar e denunciar as agressões ao ambiente. Se não há existência social sem a natureza, pois, a vida só pode existir sobre base inorgânica, é necessário que dicotomia homem/natureza (tão presente no debate da EA) seja superada, pois, a preservação de um está diretamente ligada à preservação da outro. Segundo Lessa (2012, p. 58), "a troca orgânica do ser social com a natureza é a mediação ontológica que possibilita que o ser social se constitua enquanto esfera ontológica particular no interior da totalidade do ser geral. Na tradição marxiana, tal mediação é o trabalho". Só não se pode querer não reconhecer a distinção antológica entre elas.

Da forma como os debates e as produções no campo da EA estão sendo conduzidas, estas vem favorecendo quando não contribuindo diretamente para reprodução social capitalista. 


\section{Trabalhonecessário}

Issn: 1808 - 799X

ano 11, no $17-2013$

\section{CONSIDERAÇÕES:}

A base da sociedade humana esta no trabalho, sendo este condição inerente a todo ser humano no sentido de atender a todas necessidades pessoais e sociais, caracterizando o que Marx chamou de valor-de-uso. No capitalismo, todavia, os produtos do trabalho assumem a forma de mercadoria, sendo produzidas para a troca, requerendo-Ihe seja atribuído valor.

Neste, está incluído o trabalho humano. Para Marx, o trabalho se constitui como atividade social dirigida para todos, assim como ocorria nas sociedades pré-capitalistas, quando a comunidade satisfazia suas necessidades, a partir do trabalho de seus membros e da regulação coletiva dos grupos sociais. Mesmo no caso das sociedades escravista e feudal, ambas caracterizadas pela exploração de classe, a produção estava voltada inteiramente para satisfazer as necessidades dos produtores e da classe exploradora. $\mathrm{Na}$ sociedade capitalista, alterou-se a divisão do produto do trabalho entre explorados e exploradores, enquanto uns produzem outros consomem.

No capitalismo, a produção passou a ser altamente especializada e realizada em diferentes locais. Assim ocorrendo, o trabalhador não conseguiu mais satisfazer suas necessidades a partir de sua própria produção. Portanto, o trabalhador precisou vender sua força de trabalho, passando a depender da produção de outros trabalhadores. Dessa maneira, os trabalhadores ficaram ligados somente pela possibilidade de seu produto ser aceito no mercado, o que fez surgir a competição e, consequentemente, o imperativo de aumentar a produtividade do trabalhador.

O modo de produção capitalista passou a apresentar dois tipos de separações. O primeiro, já referido, é a separação das unidades de produção. O segundo tipo ocorre no interior da unidade de produção, ou seja, a divisão entre o proprietário dos meios de produção e os produtores diretos, entre capital e trabalho.

TrabalhoNecessário - www.uff.br/trabalhonecessario; Ano 11, № 17/2013. 


\section{Trabalhonecessário}

Issn: 1808 - 799X

ano $11, \mathrm{n}=17-2013$

Marx e Engels (2008b, p. 42) indicam que, primeiramente, se torna indispensável a modificação do meio econômico que produz a situação iníqua na qual se encontra o trabalhador. A transformação social terá cabo "[...] não com a burguesia ou pela burguesia, mas sim contra a burguesia". Para tanto, cabe ao trabalhador encontrar sua força, gerando outra realidade, do mesmo modo como os capitalistas empregam sua própria força para a obtenção do lucro.

É necessário EA se despir de discurso ideologicamente dominante, será necessário se colocar no centro das questões da realidade se de fato pretende superar a sua apatia no cenário científico. Uma EA que se pretende crítica rompe com todo e qualquer postulado que não tenha compromisso com a lógica capitalista; precisa romper com práticas pedagógicas idealistas que apenas legitimam e reproduzem a pseudo emancipação; isso se aplica ao campo crítico da EA. Crítica sem uma proposta radical de superação da realidade, apenas para lembrar, radical é ir a raiz e, essa raiz é o homem, não passa de abstração vazia. 


\section{Trabalhonecessário}

Issn: 1808 - 799X

ano 11, no $17-2013$

\section{REFERENCIAS:}

ALBORNOZ, Suzana. O que é trabalho. 6. ed. São Paulo: Brasiliense, 1997.

CHASSOT, Attico. A ciência através dos tempos. 14. reimpressão. São Paulo: Moderna, 1994.

COBRA, Rubem Queiroz. Adam Smith. Página de Filosofia Moderna, 1997. Disponível em: <http://www.cobra.pages.nom.br/frmp-smith.html>. Acesso em: 01 mai 2011.

CORTES, Omar. História do trabalho, 2006. Disponível em: $<$ http://www.guatimozin.org.br/artigos/hist trabalho.htm>. Acesso em: $30 \mathrm{abr}$. 2011.

GOMES, Carlos. Antecedentes do capitalismo: mais valia, 2008. Disponível em: <http://www.eumed.net/libros/2008a/372/mais\%valia.htm>. Acesso em: 24 mai 2011.

LESSA, Sérgio. Mundo dos homens: trabalho e ser social. 3. ed. São Paulo: Instituto Luckács, 2012.

MARX, Karl. O Capital. 3. ed. São Paulo: Nova Cultura, 1988.

MARX, Karl. Manuscritos econômico-filosóficos. São Paulo: Martin Claret, 2008.

MARX, Karl; ENGELS, Friedrich. A ideologia alemã: Feuerbach- a oposição entre as concepções materialista e idealista. 3. ed. Tradução: Frank Müller. São Paulo: Martin Claret, 2008.

. Manifesto do Partido Comunista. Tradução: Sueli Tomazini Barros Cassal. Porto Alegre: L \& PM, 2009.

RUIZ, Manoel. A sociedade capitalista, 2003. Disponível em: $<$ http://www.sociedadedigital.com.br/artigo.php?artigo $=178$ item $=4>$. Acesso em: 01 mai. 2011.

SEVERINO, Antonio Joaquim. Filosofia. 2. ed. São Paulo: Cortez, 2004.

SOUSA, Humberto. A noção de capital e de mais-valia de Karl Marx. Disponível em: $\quad$ http://www.santacruz.br/v4/download/janela- 


\section{Trabalhonecessário}

Issn: 1808 - 799X

ano 11, no $17-2013$

economia/2011/3 A 2011/3 A nocao de capital.pdf>. Acesso em: 23 mai. 2011.

Data de recebimento: 08/03/2013

Data de aprovação: 10/07/2013

TrabalhoNecessário - www.uff.br/trabalhonecessario; Ano 11, № 17/2013. 